\title{
Correction to: Marrying Single Molecules to Single Cells: Protocols for the Study of the Bacterial Proto-ring Components Essential for Division
}

\author{
A. Sánchez-Gorostiaga, A. I. Rico, P. Natale, M. Krupka, \\ and $M$. Vicente
}

\section{Correction to:}

Chapter "Marrying Single Molecules to Single Cells: Protocols for the Study of the Bacterial Proto-ring Components Essential for Division" in: T. J. McGenity et al. (eds.), Hydrocarbon and Lipid Microbiology Protocols, Springer Protocols Handbooks, https://doi.org/10.1007/8623_2015_79

In a previous version of the chapter, on page 104, line 1, 'I-buffer' should have been described as containing sucrose and not glucose. This has been now corrected in print and online versions to read as:

I-buffer: $100 \mathrm{mM} \mathrm{KCl}, 100 \mathrm{mM}$ sucrose, $50 \mathrm{mM}$ HEPES (pH 7.5), 0.1 mM GDP and I mM EDTA

The updated online version of this chapter can be found at https://doi.org/10.1007/8623_2015_79 